\title{
TEJIENDO RECIPROCIDADES: JOHN MURRA Y EL CONTEXTUALIZAR ENTRE LOS AYMARA CONTEMPORÁNEOS
}

\author{
WEAVING RECIPROCITIES: JOHN MURRA AND CONTEXTUALIZATION \\ AMONG THE CONTEMPORARY AYMARA
}

\author{
Koen De Munter ${ }^{1,2}$
}

“Respetar es relacionar” (Eduardo Viveiros de Castro)

\begin{abstract}
En este ensayo, se relaciona la obra de John Murra con la de su amigo José María Arguedas y con mi propia investigación etnográfica sobre las dinámicas culturales de los aymara urbanos contemporáneos en la ciudad indígena de El Alto (Bolivia). Para caracterizar la 'tradición' cultural de los aymara -la tensión entre cambio y continuidad-, se sugiere como intuición cultural fundamental el contextualizar, es decir, el relacionar ritual y convivencialmente los diferentes espacios y tiempos dentro del mundo andino, que hace que la gente participe de la pacha. El tema del 'contextualizar', tal como se indaga en los lúcidos planteamientos de Murra y tal como se explora en Arguedas y en varios otros pensadores, nos permite entender de una manera profunda las dinámicas ecológicas, políticas y culturales que han caracterizado la tradición andina en general, y la aymara en particular. Estudiar ese sentido del contextualizar y la creatividad intercultural que produce, va a ser fundamental para abrir caminos a esas 'alternativas al mundo en el que vivimos', una búsqueda que tanto le importaba al antropólogo John Murra.
\end{abstract}

Palabras claves: contextualizar, intuiciones culturales, John Murra, José María Arguedas, Aymara, El Alto.

This essay relates John Murra's oeuvre on the one hand to the works of his friend José María Arguedas and on the other to my own etnographical research on cultural dynamics among contemporary urban Aymara in the indigenous city of El Alto (Bolivia). I introduce the notion of 'contextualization' as a pivotal cultural intuition for understanding cultural 'tradition'-that is, tension between change and continuity-among the Aymara. Contextualization refers to the ritual and convivial ways in which different spaces and times are interrelated within the Andean world. It is what makes people participate in what they call pacha. The general theme of contextualization, has been investigated throughout Murra's lucid analysis, and is also explored by Arguedas and several other thinkers. It provides a deeper understanding of the ecological, political and cultural dynamics which have characterized the Andean tradition in general, and the Aymara one in particular. It is of vital importance to study this sense of contextualization, and intercultural creativity ensuing from it, in order to open up paths towards 'alternatives to the world we live in'. That issue was of intense concern to the anthropologist John Murra.

Key words: Contextualizing, cultural intuitions, John Murra, José María Arguedas, Aymara, El Alto.

A John Murra, probablemente, le interesaría si propusiéramos como definición general de la antropología la ciencia que estudia cómo los humanos vamos participando en un 'mundo relacional' y cómo vamos transmitiendo culturalmente esta experiencia relacionante. Esta forma de describir el quehacer de la antropología a partir de una visión consecuentemente relacional ha sido implementada últimamente de forma sistemática y aguda por Tim Ingold, un antropólogo que, al igual que Murra, aboga fuertemente por la unificación epistemológica de la antropología cultural y social (y biológica) con la arqueología. En la perspectiva de Ingold, los seres vivos -no solamente los humanos- moramos (to dwell) en los 'paisajes' -en el sentido físicogeográfico, pero también latu sensu: los múltiples contextos de vida- y vamos incorporándolos (Ingold 2000). Estos paisajes nos dan -y enseñan-, por así decirlo, diferentes 'tareas de vida'. Ingold habla de taskscapes ('paisajes habilitadores'). Actuando e interactuando de tal manera con y a través de estos taskscapes, entretejiendo íntimamente lo social y lo ecológico, vamos edificando nuestra experiencia de vida, idealmente en sinfonía -en consensualidad, diría Maturana (1999)- con las experiencias de los demás. Nos vamos orientando en relación con nuestras variadas experiencias 'moradoras'. Se trata de (trans)formaciones constantes -en lo 1 Centre for Intercultural Communication and Interaction (CiCi), Universidad de Gante, Bélgica. Koenraad.deMunter@Ugent.be
2 Departamento de Antropología, Universidad de Tarapacá, Arica, Chile. kdemunter@uta.cl 
cultural, lo psicológico, lo neurológico, etc.- que nos 'habilitan' para la vida.

La perspectiva 'moradora' que interesa desarrollar en este ensayo es la que se desprende de las generosas pistas e interpretaciones que nos brindó John Murra al discurrir e indagar sobre cómo se relacionaban los 'moradores andinos' con sus múltiples paisajes, me refiero entonces tanto a los concretos pisos ecológicos entrelazados, como a los diversos 'paisajes humanos' entretejidos mediante las prácticas culturales -políticas, rituales, económicas-que supieron desarrollar las personas que moraban en estos paisajes. Estas prácticas van (entre)tejiendo a su vez diferentes reciprocidades, en lo ecológico, lo cultural y lo económico -todos conceptos estrechamente interrelacionados. Estas reciprocidades muestran facetas tanto 'positivas' como 'negativas' (por ejemplo, la venganza o la obligación generada por el don).

En este ensayo me gustaría sondear cómo la amplia visión que Murra desarrolló sobre el 'morar ecológico' en los Andes se refleja en las diferentes actuaciones contemporáneas de una reciprocidad dinámica y plurivalente. Cómo se ve reflejada en el actuar cotidiano 'contextualizador' de los aymara urbanos, cuando van entretejiendo los diferentes contextos urbanos e indígenas en una actualización permanente de los taskscapes andinos.

John Víctor Murra ha sido un guía-padrino (un jach'a ichu tata) para un sinnúmero de personas. Aun si yo no lo conocí personalmente, cuando estudiaba antropología en Flandes (la parte neerlandófona de Bélgica) hace unos quince años, su obra -y la presencia humana que se iba plasmando a través de ella- llegó a significar algo muy fuerte para mí, ya que yo estaba estudiando antropología en una tradición académica donde las ciencias sociales estaban -y siguen- volcadas plenamente en los estudios de Africa (por el pasado colonial de Bélgica en Congo). También se estudia Asia, pero generalmente se dedica poca atención a América Latina (excepto en el campo de las ciencias de la literatura), y mucho menos aún a los Andes. Tuve que ir entonces en busca de fuentes de información, de amautas que me contaran y enseñaran 'a la distancia'. Uno de los guías fundamentales para aproximarme del tiempo/espacio andino llegaría a ser John Murra, cuyo libro Formaciones..., con su tapa de tonos verdes entrelazados, no ha dejado de acompañarme, cada vez que necesitaba poner mis propias aproximaciones etnográficas en el debido relieve histórico-antropológico. En aquel libro, se me revelaban vivamente las variadas facetas de los mitmaq y del reino Lupaqa, los variados usos del tejido en la construcción de reciprocidades y compromisos, y otros muchos temas. Allí se enseñaba de una forma muy bienvenida y estimulante para alguien como yo, quien se consideraba una suerte de 'huérfano andino' al querer estudiar antropología desde Flandes.

Antes de abordar el aprendizaje propiamente antropológico y etnohistórico vía los textos de Murra, ya había podido apreciar la obra de su compañero de ruta, José María Arguedas, puesto que de primera formación soy filólogo románico. Al Arguedas escritor de Los Ríos Profundos, que me había acompañado en varias andanzas 'precientíficas' por los Andes, le sucedería el Arguedas antropólogo. En mi tesis de grado de antropología investigué precisamente la fuerza epistemológica que surgía de la combinación de esos dos modos de edificar conocimiento, uno más artístico, otro más científico, pero ambos movidos por una misma pasión con los 'paisajes' humanos, en este caso andinos. Durante aquel estudio descubrí la profunda amistad y complicidad profesional que unía a John Murra y José María Arguedas. Vale la pena indagar un poco la complementariedad entre la obra de estos dos amigos y colegas antes de pasar a las dinámicas culturales de los aymara contemporáneos y a cómo se pueden interpretar a partir de la perspectiva interpretativa combinada de Murra y Arguedas.

En la obra antropológica de Arguedas de los años cincuenta me llamaban la atención sus ideas -y esperanzas- acerca de lo que en textos anteriores he llamado un cierto 'mestizaje económico' (De Munter 2004). Aun si Arguedas siempre subrayaba la importancia de asumir plenamente los artefactos 'mestizos' que habían resultado de la interacción (post) colonial $^{1}$, a su modo de ver ese intenso proceso de transculturación, hasta las primeras décadas del siglo veinte, no había llevado las culturas andinas 'subalternas' a "asimilarse definitivamente hacia la cultura occidental" ( $c f r$. una cierta interpretación limitada de la teorización antropológica de esa época sobre la aculturación elaborada por Herskovits y Linton, entre otros). Para Arguedas, esto se debía a lo que él consideraba una diferencia irreconciliable en el corazón mismo de las respectivas tradiciones culturales: el actuar económico. En su opinión, fueron las maneras radicalmente diferentes de manejar 
'la economía' (en el fondo, para él, anunciando a Polanyi y los substantivistas, y también a John Murra, no había tal forma única de 'economía' y mucho menos sería ésta la 'capitalista') las que explicaban por qué, a pesar de todas las interacciones que se dieran, las dos tradiciones seguían navegando por cauces culturales básicamente separados. Según Arguedas, este 'eje' económico "en la [cultura] occidental era y es mercantil e individualista; en la peruana antigua, colectivista y religiosa" (Arguedas 1975:25²). Se mantenía una profunda barrera entre ambas prácticas económicas, una más bien considerada como actividad 'autónoma', otra como un actuar económico mucho más interrelacionado y entretejido culturalmente (tal como lo estudiaba John Murra a través de sus aproximaciones a la organización humana en los Andes). Pero, en palabras de Arguedas, esa barrera entre los respectivos actuares económicos había sido "antiguamente". Se vio en la obligación de indagar y reflexionar sobre los bruscos cambios desestructurantes que implicaría la irrupción modernizadora a mediados del siglo veinte para la tradición y el 'ecosistema' andinos. Los cauces separados se juntarían y Arguedas se esmeró para entender y analizar las dinámicas y las consecuencias de ese proceso irreversible y preocupante.

Sin poder profundizar aquí en la compleja y ambivalente evolución del pensamiento arguediano sobre el mestizaje cultural (Manrique 1995), podemos decir que, en base a sus conocidos estudios sobre los "ex indios del valle del Mantaro" y sobre la comunidad en Puquio -que él conocía tan bien-, Arguedas llegó a considerar que:

en cuanto el indio, por circunstancias [históricamente] especiales, consigue comprender este aspecto de la cultura occidental, en cuanto se arma de ella, procede como nosotros; se convierte en mestizo y en un factor de producción económica positiva. Toda su estructura cultural logra un reajuste completo sobre una base, un 'eje' (Arguedas 1975:26).

Arguedas, en aquella época por lo menos, y a pesar suyo, parecía colocarse estratégicamente del lado de la 'economía occidental' o, mejor dicho, consideraba esta transición como la única salida posible ("comprender y asimilar el concepto occidental de la propiedad y del trabajo").
Efectivamente, a pesar del profundo cariño que sentía por los grupos indígenas en toda su dimensión 'colectivista-religiosa', de alguna manera llegó a preconizar ese 'mestizaje económico' como estrategia de 'sobrevivencia cultural'. La transculturación en los Andes giraría alrededor de una adaptación en lo económico de parte de los grupos subalternos. Siendo capaces de complementar "la economía de los comerciantes y la de los indios" -y solamente así-, las comunidades serían capaces no solamente de sobrevivir como tradición indígena en medio de la tormenta modernizadora, sino incluso de fortalecer su "personalidad cultural" (Arguedas 1975:11). Esto no ocurriría con las comunidades conservadoras, cerradas a cualquier apertura, las que terminarían por desvanecerse culturalmente (de ahí la necesidad de una 'antropología de la urgencia').

Para muchos, esta visión sobre un estratégico 'mestizaje económico', concepto que Arguedas no llegó a elaborar explícitamente en sus escritos antropológicos, aun si la idea está claramente muy presente, sobre todo también en su producción literaria-, suena simplemente como una versión particular de la omnipresente ideología del mestizaje. Indudablemente, es una de las razones por las que, entre grupos indígenas más radicales, a menudo se mira a Arguedas como un mestizo más, externo a la causa propiamente nativa. Sin embargo, ellos no toman en cuenta que el pensamiento arguediano no se quedó allí, y que discurriría sobre otros y nuevos aspectos. Y pensando entonces en su trayectoria artística o literaria de la década de 1960, y sobre todo en su última creación artística-empezada como estudio etnográfico-, El Zorro de Arriba y el Zorro de Abajo (en adelante Los Zorros). Es en aquella 'obra total', cuya génesis pudo seguir de cerca John Murra, que el autor andino supo aprovechar la sensibilidad combinada de ambas 'disciplinas', la artística y la antropológica, para acercarse de los fuertes cambios que estaba atravesando su país, y más específicamente de los efectos culturales de la expansión urbana. John Murra, al referirse al conjunto de la obra de su compañero peruano, destaca aquellas "coincidencias interesantes donde hay novela y una monografía antropológica sobre el mismo tema" (Murra y López-Baralt 1998:289) y expresa su convicción de que la antropología "sólo puede enriquecerse de estos lazos con la literatura, con la poesía”. En el pasaje citado, Murra se está refiriendo a Yawar fiesta y a un estudio sobre Puquio. Aquí me refiero a la riqueza combinadora y liminal 
(en el sentido etimológico de 'peldaño': que permite el tránsito entre diferentes espacios/tiempos) que se encuentra en los multifacéticos Zorros: registros orales y escritos, discursos literarios y etnográficos, formatos epistolares y míticos se entrelazan para inquirir el supuesto desarraigo de los migrantes indígenas en la ciudad Chimbote con su industria pesquera y para evocar los contactos interculturales que se producían simultáneamente. Indudablemente, en Los Zorros Arguedas intentaba mirar más allá del desencanto que pudo haber significado para él la cruda realidad del 'mestizaje económico' en Chimbote. El problemático destino de la tradición indígena en contexto urbano es un tema central de la obra, pero de esta indigeneidad desplazada emana sobre todo una imaginación re-encantadora que interrelaciona los múltiples tiempos/espacios existenciales que se van (des)encontrando en la ciudad y que van conformando así unos desafiantes 'paisajes-tarea' o taskscapes.

El Zorro de Arriba y el Zorro de Abajo logra evocar toda esa liminalidad del proyecto urbano, multicultural y moderno. Allí se dan cita e interactúan mucho más que solamente 'los dos mundos': uno occidental y supuestamente moderno, otro indígena y supuestamente tradicional. 'Pero ahora hay mundos de más arriba y mundos de más abajo', dice literalmente uno de los zorros en su diálogo transhistórico (un diálogo que se refiere al manuscrito de Huarochirí, traducido y editado por Arguedas, y considerado por Murra "el único monumento literario quechua").

Más que sólo descripciones de desarraigo indígena, en Los zorros hay mucho 'baile de los mundos' y se rescata poéticamente la fuerza de la creolización entre los respectivos 'pisos existenciales'. Ciertamente, hay preocupación e indignación por la explotación del colonialismo interno e internacional, pero no hay resignación. Los 'paisajes' del mundo andino -incluyendo los cantos primigenios de los patos de la altura, por ejemplo- seguían moviéndose continuamente, al igual que las personas. Si "escribía contra la muerte", escribía sobre todo para la vida. Una vida que suponía la experiencia de los migrantes andinos, que habían bajado a las nuevas ciudades industriales, pero también las experiencias de muchos otros grupos ${ }^{3}$. El esfuerzo creativo -y yo diría, propiamente antropológicode Los Zorros radica sobre todo ahí, en esa visión abarcadora y relacionadora. La tarea 'truncada' de Arguedas la acompañó y la continuó desde otra perspectiva abarcadora su compañero John Murra, quien subrayó lo científicamente acertado de "la intuición" arguediana. Aparte de esto, a John Murra, al igual que a otros colegas que se comprometieron con estudiar los complejos y salpicados 'paisajes' andinos, le gustaba siempre recordar lo "humanistas" que fueron los planteamientos de Arguedas (Murra y López-Baralt 1998).

Personalmente, Los Zorros significaron en primer lugar un enlace directo con mi propio trabajo de campo etnográfico en los años noventa, el caso de los 'residentes' Aymara en la ciudad de El Alto, ciudad que durante mucho tiempo fue considerada la 'hermana Cenicienta' de la ciudad de La Paz, pero ahora llamada a veces la 'capital andina'. Al igual que en Chimbote, se trata de migrantes indígenas en medio de los 'hervores' de una gran ciudad. Esta, sin embargo, aparte de ser bastante más grande que Chimbote, se encuentra en pleno corazón andino, cerca del lago Titicaca y de los cerros sagrados. En El Alto, la mayoría de los habitantes claramente ya ha logrado -a menudo laboriosamente- un claro nivel de mestizaje económico o complementación económica, combinando una participación en el mercado de las grandes ciudades y una interacción en base a lazos de reciprocidad con el mundo de las comunidades originarias (Temple 2003). Hacía falta investigar cómo transitaba su tradición cultural en medio de ese panorama de cambios económicos y sociales. Fueron aquella ciudad y sus habitantes -la mayoría de ellos indígenas- los que me permitieron retomar de manera muy concreta y aguda la pregunta fundamental que movía a John Murra en su búsqueda de una 'nueva hipótesis andina'. En las palabras de Franklin Pease: “...la preocupación fundamental es para Murra lo que permanece por encima de los cambios, la experiencia humana acumulada, decantada..."4.

En cierta forma, y a pesar de que no existe una relación intrínseca entre la idea arguediana de un estratégico mestizaje económico con alguna pista conceptual de Murra, las obras de Arguedas y Murra llegaron a ser fuertemente complementarias para mi investigación sobre las dinámicas culturales a través del tiempo-espacio andino, ya que ambas obras dan muestra de un continuo interés por estudiar la interrelación entre las prácticas económicas, sociales y culturales. No se trata evidentemente de compararlas, pero, puestos a reflexionar aquí sobre la significación de la obra murriana, diría que ésta me brindaba 'otra' 
perspectiva abarcadora, que ponía en otro relieve -más 'amplio' tal vez- las aproximaciones a lo mejor 'demasiado' vividas ${ }^{5}$ de Arguedas. Murra participaba también de la realidad andina, pero de una manera y desde una posición que le permitió elaborar una mirada más 'serena'. Arguedas estaba definitivamente pero también fatalmente implicado en los mismos procesos que intentaba dilucidar. $\mathrm{La}$ especie de schismogenesis interna que caracteriza su obra y su vida dificulta -pero no imposibilitala implementación cabal de sus planteamientos. La obra de John Murra ofrece una visión de larga duración, en la que el 'horizonte' de referencia se presenta de forma más pausada y coherente. Esto me ayudó mucho para atreverme precisamente a determinar -más allá de los esencialismos fáciles- un hilo conductor para el caso de la tradición aymara, una corriente creadora que subyace debajo de todos los impactantes cambios.

Puestos a investigar las dinámicas culturales entre los aymara contemporáneos en El Alto, me intrigaba la compleja relación entre cambio y continuidad (Guaygua et al. 2000) y el tema de 'la experiencia humana decantada'. Si se había dado un masivo mestizaje económico en el sentido de Arguedas, se podía suponer que algo debió de haberse alterado en el mismo 'fundamento' de la tradición indígena. Sin embargo, en el terreno se puede comprobar que, a pesar de la presencia implacable del Mercado hegemónico, aún se siguen practicando muchas de las antiguas sabidurías 'económicas' y 'religiosas'. Una gran mayoría de familias aún se consideran como jaqi-gente aymara- e indígenas, todavía (inter)actúan como aymara, pero de maneras obviamente diferentes que antes. Me interesaba entonces ir entendiendo las estrategias cotidianas mediante las que grupos como los aymara en El Alto estaban logrando esta 'progresión' cultural.

Al comenzar mi investigación doctoral, a mediados de la década de 1990, busqué una vía no esencializadora para describir y analizar aquella continuidad cultural en los Andes. Para hacer esto, recurrí a una aproximación comparativa del actuar cultural mediante el concepto de las intuiciones culturales (Pinxten 1997), las que se podrían definir como principios subyacentes que le otorgan coherencia -a menudo de forma latente- a la gran diversidad de prácticas que se transmiten dentro de un grupo cultural. Las intuiciones culturales se consideran como una herramienta heurística y hermenéutica: ayudan al antropólogo a determinar e interpretar las diferentes acentuaciones o configuraciones de nuestras potencialidades humanas universales. Estas acentuaciones son culturalmente relativas. Una de las características más importantes de este concepto es que las intuiciones culturales se formulan, se evalúan y se manejan en constante diálogo y negociación con los consejeros/informantes en el 'campo'. El objetivo de trabajar mediante el concepto de intuiciones culturales es básicamente comparativo. Así por ejemplo, en términos generales, una de las intuiciones centrales para la tradición occidental sería la denominada 'perspectiva divina', una tendencia a mirar el mundo como si uno estuviera fuera del mismo ${ }^{6}$. Es una intuición que permite entender, por ejemplo, cómo funciona 'la' ciencia en occidente (objetivizante, categorizadora, colocándose fuera de la realidad, como el dios cristiano) y también cómo en esta tradición se ha tratado predominantemente a la naturaleza como si estuviera allí para que la domináramos y explotáramos, incluso como si no formáramos parte intrínseca de ella. En otras tradiciones se darán acentuaciones muy diferentes.

Para el caso de los aymara ${ }^{7}$ en El Alto, retuve un tándem de intuiciones fuertemente entrelazadas entre sí. La primera la formulé como 'el contextualizar', la segunda como "un sentido de la plurivalencia". En el fondo, la segunda es como una puesta en escena 'axiológica' de la primera. No puedo profundizar aquí en la trayectoria que me permitió llegar a esta formulación (De Munter 2007), pero básicamente se podría decir que el 'contextualizar' se refiere a este principio que hace que a través de sus prácticas culturales las personas se dediquen a relacionar atentamente $-\mathrm{y}$ a menudo ritualmente, como en las ch'allas- los diferentes contextos (temporales y espaciales) de vida, al igual que los diferentes 'valores' que se otorgan a elementos o procesos que marcan esta vida (de ahí el sentido de la 'plurivalencia': todo lo que participa de la pacha tiene aspectos o efectos tanto 'buenos' como 'malos', simultánea o alternativamente y siempre recíprocamente. Aparte de la interacción propiamente etnográfica, fueron las exploraciones bibliográficas las que coadyuvaron para formular estas intuiciones. Se trataba sobre todo de los estudios etnohistóricos de John Murra, de los estudios lingüísticos de Martha Hardman y de estudios de carácter propiamente etnográficos, como los de Arnold y Yapita, entre otros. 
Respecto de la teorización del concepto de 'contextualizar' quiero recordar un elocuente pasaje en Formaciones..., donde Murra dice que "los tejidos integran muchos e inesperados contextos" (Murra 1975:169 [énfasis mío]). La idea de "integrar contextos' expresa muy bien la forma de la que Michael Cole, en su obra seminal sobre una psicología cultural, reivindica y elabora teóricamente el concepto de 'contextualización' (Cole 1996). Cole propone abrir o romper las clásicas aproximaciones cognitivas mediante la pista de la contextualización cultural. Dinamiza el término conocido -y aceptado- de 'contexto', considerándolo como contextualización, en su dimensión ecológica y cultural más incluyente y dinámica. Esto le permite interpretar el concepto de la contextualización en su sentido etimológico: 'to weave together ${ }^{\text {' }}$. La metáfora del 'entre-tejer' es importante en la medida que nos enseña que el contexto no es sencillamente aquello que rodea, sino que se trata de una "....relación cualitativa entre al menos dos entidades analíticas (hilos), que son momentos de un mismo proceso. Las fronteras entre 'la tarea y su contexto' no son nítidas o estáticas sino que ambiguas y dinámicas" (Cole 1996:135 [traducción mía]). Es el actuar cultural que va entretejiendo constantemente sujetos (objetos) y contextos como 'taskscapes'.

Las ya mencionadas ch'allas ilustran muy bien cómo ese contextualizar-dentro-de-la-pacha(mama) se expresa en prácticas rituales. Lo mismo podría decirse de la fuerza relacionadora que emana de los tinku, en que permiten desarrollar la vital secuencia tinku/taypi/kuti (De Munter y Note 2008; Platt 1996). Estas prácticas rituales cultivan la indispensable atención que las personas deben mantener hacia las múltiples interacciones que van entretejiendo los contextos de vida y hacia las interrelaciones que resultan de ellas. Producen la experiencia del contextualizar que hace "caminar" ${ }^{\text {' }}$-o existir-a la gente. Fomentar esta experiencia y 'dejarse criar' por ella es lo que se podría llamar la cosmopraxis (De Munter y Note 2008) ${ }^{10}$ que garantiza el constante cambio o kuti cotidiano.

Indudablemente, y volviendo a El Alto, la pobreza material y la injusticia generalizada siguen siendo un problema mayor en esta ciudad indígena, pero como antropólogo no puedo sino apreciar la muy rica progresión de prácticas culturales que siguen interconectando y complementando cotidianamente los múltiples contextos que se presentan en esta ciudad (incluyendo los contextos de la colindante ciudad de La Paz). Así, conversando con mis consejeros alteños aymara sobre las relaciones entre campo y ciudad, varios de ellos llegaron a confirmar, a veces para su propia sorpresa, que una forma extendida de 'comunidad' -siguiendo los principios de la comunidad originaria, pero ya en proceso de creolización con los diferentes principios urbanossí se seguía practicando en cierto modo en la urbe. Según ellos, esto se refleja notoriamente con ocasión de las conmemoraciones de los muertos durante las cuales se presta especial atención a la relación seminal con los achachilas (los antepasados, pero también los elementos tutelares del paisaje que se asocian con ellos). Estas conmemoraciones siguen celebrándose asiduamente según los tradicionales principios de reciprocidad y complementariedad en las casas (utanaka) y en los cementerios, tanto en El Alto como en las comunidades altiplánicas (De Munter 2007; Fernández Juárez 2002).

Hasta cierto punto, los planteamientos que iban formulando acerca de la 'comunidad extendida' me sonaban como un eco contemporáneo de la lectura etnohistórica que hizo John Murra de los aymara pre-colombinos cuando detectaba los múltiples 'hilos' que se entretejían para dar vida al archipiélago 'mediterráneo' y a la ecosimbiosis interzonal. De alguna manera, los aymara contemporáneos, viajando -materialmente y simbólicamente- entre la ciudad (a veces también desde países vecinos) y sus comunidades de origen, pero también visitándose (tumpaña) entre los diferentes barrios o zonas de la ciudad, siguen aplicando un sentido 'viajante' o 'desterritorializado' de la 'identidad'. Parecería estar jugando una concepción de identidad diferente, lejos de cualquier interpretación esencialista o territorial. De ahí nace otra impronta de comunidad, otra forma de hacer comunidad. Una comunidad múltiple y fragmentada donde se maneja un sentido del ayni (prácticas de reciprocidad) de una manera probablemente más desengañada y 'realista' - en la ciudad pesa más la 'obligación' de ayudar financieramente-, pero donde este ayni sigue practicándose con convicción y donde sigue considerándose éste como un eje principal de la cohesión social. Murra subrayó cómo las prácticas históricas del ayni siempre habían sido ambivalentes, incluyendo tanto "el deber de vengar" como el de prestar ciertos servicios (aparte de la acepción clásica "de trabajo recíproco"). Esta ambivalencia forma parte de lo que se ha llamado aquí el sentido de la plurivalencia y acompaña necesariamente a la 
intuición del contextualizar. Murra afirmó que los variados y a veces contradictorios significados de la reciprocidad andina estaban -y están- íntimamente ligados a cómo se iba organizando realmente la convivencia social (Murra 1975:307). De este modo se ponían en práctica los principios de la fundamental complementariedad ecológica y cultural, lo que él llamaba "el logro andino" (Castro et al. 2000:141).

Sin duda alguna, los efectos de la lógica de la colonización han sido devastadores. Se desestructuró fuertemente aquel importante pero siempre frágil principio de la complementariedad activa entre pisos ecológicos, pero las intuiciones subyacentes del contextualizar y del sentido de la plurivalencia no quedaron aniquiladas, sino que siguen guiando a las personas. Esto lo testifican, por ejemplo, las actuales reivindicaciones de las antiguas formas de organizarse políticamente y socialmente (el ayllu) y sobre todo, si pienso en mi propio trabajo de campo, esto se aprecia claramente en las prácticas diarias de 'la gente común'. Ellos emprenden, desde sus familias y desde la convivencialidad, la tarea cotidiana de fomentar la atención -ritual y social-a la interrelación de los diferentes tiempos y espacios que van componiendo su (plurivalente) experiencia de vida. Esta actitud siempre ha marcado fundamentalmente, como nos lo (de) muestra Murra, las formas de vida en los Andes. Es en estas formas de vida, por ejemplo, que se desarrollan lo que Dominique Temple y sus colegas investigadores llaman las "interfases" de sistemas económicos, que articulan "dos economías" y van extendiendo el territorio de 'la' comunidad (Temple et al. 2003:4911). Estos autores quieren mostrar “... cómo las comunidades aimaras -a pesar de articularse con esferas mercantiles desde mucho tiempo- ponen en acción múltiples relaciones de reciprocidad de carácter económico ..." (Temple et al. 2003:192).

Todo esto me confirma la utilidad de manejar el contextualizar como una intuición cultural central para la tradición aymara, y, por extensión, para la tradición andina. Esa convicción de la importancia de interrelacionar y combinar cuidadosamente paisajes, tiempos y experiencias diferentes estaba muy presente en Arguedas, y fue indagada y teorizada de manera más patente por John Murra ${ }^{12}$. Llama la atención que, a pesar de tanta colonialidad del poder, este espíritu contextualizador sigue siendo capaz de producir resistencia $y$ encuentro $^{13}$. Desde una visión de larga duración tal como nos la proporciona Murra, no sorprende que en el actual escenario político de Boliva exista una relación estrecha entre las prácticas convivenciales (Illich 1978) de un sector importante de la población y las dinámicas insubordinantes que surgieron desde esos mismos grupos (Lazar 2008).

¿Qué se podría decir, finalmente, desde una perspectiva murriana sobre el pionero experimento histórico que están intentando desarrollar Evo Morales y su Movimiento al Socialismo en Bolivia, un proceso que indudablemente fue inspirado por los principios de la cosmopraxis andina? Aquí ha jugado desde el principio un pensamiento incluyente, es decir, se ha invitado a todos los sectores de la sociedad a participar en el proceso de 'evolución democrática'. Al mismo tiempo, se tenía plena conciencia de que para llevar a cabo tamaño proyecto sería necesaria una clara confrontación entre diferentes y hasta opuestas 'visiones' sobre el país, por lo que se podría decir que jugaba la dinámica relacionadora del taypiltinku, capaz de producir un paulatino pero duradero (pacha)kuti. Todos sabemos que las visiones e ideologías que están en juego en Bolivia son radicalmente opuestas en variados aspectos, pero los que se identifican con el proyecto de Morales saben que solamente así se puede llegar, finalmente, a cambios sustentados por todos los integrantes de una futura sociedad descolonizada.

John Murra demostró cómo varios de los principios políticos precolombinos, como por ejemplo el sistema de los mitmaq, ya estaban en plena transformación antes de la llegada de los españoles. Sin embargo, probablemente no le sorprendería que ciertas convicciones subyacentes al actuar cultural aymara -en este texto hemos hablado de intuiciones culturales- se hayan mantenido y hayan vuelto a participar plenamente en el debate societal. A mi modo de ver tampoco le sorprendería, por otra parte, la crítica creciente de parte de un grupo de pensadores indígenas, que preconizan una descolonización más radical -pero también más unilateral-y proponen implementar el principio del ayllu a nivel del Estado. Todo esto forma parte de un proceso de largo aliento, de un tinku multiplicado y complejísimo que ojalá algún día pueda ser también conciliador.

A veces me pregunto cómo hubiera evaluado John Murra este complejo proceso de 'revolución descolonizadora' que marca la Bolivia contemporánea, 
él que decía de sí mismo que era un "graduado de la guerra civil española" y "no de la universidad de Chicago'. En Murra está siempre presente la idea de que la ciencia tiene que ser una ciencia de la acción y del compromiso, pero está igualmente presente la idea de que siempre es necesario sacar lecciones de los momentos revolucionarios, pensemos por ejemplo en su apreciación, a posteriori, de los anarquistas del POUM (Castro et al. 2000:29). Por otro lado, y como ya se ha subrayado aquí, Murra ofrece este conocimiento en profundidad y en sutileza en relación a las formaciones y organizaciones andinas históricas a las que tanto les gusta referirse, tanto a los oficialistas del movimiento de Morales como a sus críticos del lado indígena más radical.

De todas maneras está claro que, por debajo de los a veces vehementes procesos revolucionarios que caracterizan la Bolivia de la primera década del siglo XXI, es "la gente de abajo" la que sigue organizándose orgánicamente según antiguas dinámicas andinas, reactualizadas y recontextualizadas a diario, y son estos mismos grupos los que siguen transformando de a poco el mundo andino. La fuerza humana que emana de todo ello.

Eduardo Viveiros de Castro, el antropólogo brasileño de quien es la cita inicial que introduce este ensayo, aboga por una teoría antropológica recíproca e imaginativa. En su concepción, ya no se trata entonces de elaborar una "mirada antropológica" (sea ésta racionalizadora o relativizadora) para determinar cómo es "el indígena", sino que más bien la antropología debería de empeñarse en valorizar y relacionar la mirada indígena como "condición de un mundo posible"14. O, en las palabras de John Víctor Murra: "Yo soy antropólogo porque me interesa una alternativa al mundo en el que vivimos" (Castro et al. 2000:98).

Agradecimientos: Mis sinceros agradecimientos a los evaluadores, a Vicky Castro, Calogero Santoro, Hans Lindahl, Sandra Acuña, Sandra Coppia y a nuestros consejeros en El Alto.

\section{Referencias Citadas}

Arguedas, J.M.

1975 Formación de una Cultura Nacional Indoamericana. Siglo XXI, México.

1976 Señores e Indios (Acerca de la Cultura Quechua). Arca-Calicanto, Buenos Aires.

1988 [1971] El Zorro de Arriba y el Zorro de Abajo. Horizonte, Lima.

Castro, V., C. Aldunate y J. Hidalgo, editores

2000 Nispa Ninchis. Conversaciones con John Murra. IEP/ IAR, Lima.

Cole, $\mathrm{M}$.

1996 Cultural Psychology. A Once and Future Discipline. The Belknap Press of Harvard University Press, Cambridge.

De Munter, K.

2004 Five centuries of compelling interculturality: The Indian in Latin-American consciousness. En Culture and Politics, Identity and Conflict in a Multicultural World, editado por C. Longman, R. Pinxten y G. Verstraete, pp. 89-114. Berghahn Books, New York \& Oxford.

2007 Nayra, Ojos al Sur del Presente. Aproximaciones Antropológicas a la Interculturalidad Contemporánea. Latinas Editores-Centro de Ecología y Pueblos Andinos, Oruro.

De Munter, K. y N. Note

2009 Cosmopraxis and contextualizing among the contemporary Aymara. En Worldviews and Cultures. Philosophical Reflections from an Intercultural Perspective, editado por N. Note, R. Fornet-Betancourt, J. Estermann y D. Aerts, pp. 87-102. Springer Verlag, Heidelberg.

Estermann, J.

2006 Filosofía Andina (Sabiduría Indígena para un Mundo Nuevo). Instituto Superior Ecuménico Andino de Teología, La Paz.
Guaygua, G., A. Riveros y M. Quisbert

2000 Ser Joven en El Alto (Rupturas y Continuidades en la Tradición Cultural). Programa de Investigación Estratégica en Bolivia, La Paz.

Illich, I.

1978 La convivencialidad. http://habitat.aq.upm.es/boletin/ n26/aiill.html.

Ingold, T.

2000 The Perception of the Environment. Essays in Livelihood, Dwelling and Skill. Routledge, London.

Fernández Juárez, G.

2002 Aymaras de Bolivia. Entre la Tradición y el Cambio Cultural. Abya Yala, Quito.

Lazar, S.

2008 El Alto, Rebel City. Self and Citizenship in Andean Bolivia. Duke University Press, Durham and London.

Manrique, $\mathrm{N}$.

1995 José María Arguedas y la cuestión del mestizaje. En Amor y Fuego. José María Arguedas: 25 Años Después, editado por M. Martínez y N. Manrique, pp. 77-91. DESCOCEPES-SUR, Lima.

Maturana, $\mathrm{H}$.

1999 Transformación en la Convivencia. Dolmen Ediciones, Santiago.

Medina, J.

2002 La Vía Municipal hacia la Vida Buena. Garza Azul, La Paz.

Murra, J.V.

1975 Formaciones Económicas y Políticas del Mundo Andino. IEP, Lima. 
Murra, J.V. y M. López-Baralt, editores

1998 Las Cartas de Arguedas. Pontífica Universidad Católica del Perú, Fondo Editorial, Lima.

Pease, F. (citado en la nota 4) 1975 Prólogo. En Formaciones Económicas y Políticas del Mundo Andino, pp. 9-18. IEP, Lima.

Platt, T.

1996 Los Guerreros de Cristo. Cofradías, Misa Solar, y Guerra Regenerativa en una Doctrina Macha (Siglos XVIII-XX). ASUR-Plural, La Paz.
Temple, D., F. Layme, J. Michaux, M. Gonzales y E. Blanco 2003 Las Estructuras Elementales de la Reciprocidad. TARI, Plural Editores, Carrera de Antropología y Arqueología UMSA, La Paz.

Viveiros de Castro, E. 2002 O Nativo Relativo. http://www.scielo.br/scielo. php? script=sci_arttext $\&$ pid $=$ S0104-9313200200010000 5 (27 de agosto 2007)

Yampara, S., S. Mamani y N. Calancha

2007 La Cosmovisión y Lógica en la dinámica socioeconómica del Qhatu/Feria 16 de julio. PIEB, La Paz.

\section{Notas}

1 Lo contrario, el rechazo a la producción mestiza -por ejemplo, la categoría del "textil etnográfico"- y la preferencia hacia una autenticidad precolombina, significaba para él un "monstruoso contrasentido" (Arguedas 1976:215).

2 Véase el ensayo La Sierra en el proceso de la cultura peruana (Arguedas 1975:9-27).

3 En esta obra comparten el escenario lo afroamericano, lo criollo, lo mestizo, lo indígena y lo norteamericano.

4 "Lo andino se aprecia en los estudios de Murra en una permanente dialéctica entre la continuidad y los cambios históricos. Si la insistencia fue siempre en lo último, a la luz de los distintos procesos, organizaciones urbanas y estatales, la precocupación fundamental es para Murra lo que permanece por encima de los cambios, la experiencia humana acumulada, decantada, frente a la necesidad de obtener y diversificar los recursos que hacen posible la vida" (Pease, en el prólogo a Murra 1975:13).

5 'Si lo oigo, si lo veo, si participo, si entiendo lo que me dicen, yo aprovecho muy bien'. Y también: 'Yo tengo muy mala preparación teórica. Lo que hago es que huelo los problemas y, antes de analizarlos, los vivo'. Murra, al citar estas afirmaciones de Arguedas en su texto José María Arguedas: dos imágenes, añade que "Este no es el Arguedas quejoso, a quien el insomnio agobia. Es otro Arguedas, orgulloso y competente" (Murra y López-Baralt 1998:272).

6 Esto no quiere decir que no haya otras potencialidades culturales en las sociedades occidentales (por ejemplo, las 'holísticas'), pero la intuición cultural se refiere a lo que se presenta como el panorama dominante o hegemónico. Otra intuición relacionada a la perspectiva divina sería el atomismo: una tendencia a categorizar, a individualizar (el derecho/deber a la auto-realización) y/o a especificar, a costa de una visión (ética) del conjunto ( $c f r$. lo competitivo a nivel individual).

7 Trabajé sobre todo con familias más bien 'tradicionales', que aún fomentaban claramente las costumbres -la lengua aymara, por ejemplo-y que solían viajar a menudo a sus comunidades de origen por razones festivas y económicas.

8 "The frequency with which metaphors of weaving, threads, ropes and the like appear in conjunction with contextual approaches to human thinking [y como antropólogos, podríamos decir, aproximaciones del actuar humano en general] is quite striking. (...) In short, because what we call mind works through artifacts, it cannot be unconditionnally bounded by the head or even by the body, but must be seen as distributed in the artifacts which are woven together and which weave together individual human actions in concert with and as a part of the permeable, changing, events of life" (Cole 1996:135). Véanse también la "consensualidad" en Humberto Maturana (1999) y el "enskillment" en Tim Ingold (2000).

9 Me refiero al lema conocido 'hay que caminar como jaqil gente'.

10 "Cosmopraxis can be considered-partly-analogous to this phenomenological and post-modern approach in that it also focuses on the immediate, the 'unmediated. However, where the Western approach is limited to a theoretical, cognitive effort of bringing into awareness this forgotten dimension, cosmopraxis describes the actual praxis of living this unmediated experience. It concerns a multiple encounter lived through different practices such as barter, ritual healing, ritual fighting, political organisation, and so on. It refers to coping with the world in an active way". (De Munter y Note 2009:89).

11 "Trabajar la interfase de sistemas es establecer una traducción del valor de prestigio en valor de cambio; esto es un problema bastante difícil. Entonces, hablar de dos economías, de interfase de sistemas, conduce a la idea de respetar una territorialidad propia para cada campo. A veces, es muy fácil. Por ejemplo, aquí, en Bolivia, el territorio de las comunidades, de los ayllus, puede ser un campo de reciprocidad, y, fuera del ayllu, puede ser campo para el intercambio.(...)" (Temple 2003:49).

12 Esta idea se encuentra bajo diferentes formas en la obra de varios estudiosos de la 'sabiduría' andina, pienso, por ejemplo, en Josef Estermann (2006), Javier Medina (2002) y Simón Yampara (Yampara et al. 2007).

13 Personalmente, suelo usar el término de 'prácticas liminales' (no en el sentido de Van Gennep o Turner, sino en su sentido etimológico y relacionador), refiriéndome a la capacidad -fomentada históricamente a través de la colonialidad- de que las personas han ido aprendiendo a manejar experiencias combinadas, moviéndose entre diferentes espacios/tiempos, atravesando 'peldaños' -limen- entre espacios culturales (siempre con la posibilidad de 'regresar') y uniéndolos, muchas veces críticamente. En mi tesis doctoral, para el caso concreto de la tradición aymara, menciono la importancia de la rítmica tinku-taypi-kuti. El cambio paulatino y vital que proviene del encuentro imprescindible entre los supuestos 'opuestos', que no lo son.

14 "Respeitar não é tolerar. Quem gostaria de ser tolerado? Respeitar é relacionar. Em Antropologia, todas as relações são possíveis. Só uma é impossível: a ausência de relação" (http://www.ufmg.br/online/arquivos/001639.shtml). 
